Cite this: Dalton Trans., 2014, 43, 10033

Received 20th February 2014, Accepted 9th May 2014

DOI: $10.1039 / c 4 d t 00544 a$

www.rsc.org/dalton

\title{
Low temperature synthesis of ionic phosphates in dimethyl sulfoxide $\uparrow$
}

\author{
Martin Mangstl, ${ }^{a}$ Vinicius R. Celinski, ${ }^{a}$ Sebastian Johansson, ${ }^{a}$ Johannes Weber, ${ }^{a}$ \\ Feng $A n^{b}$ and Jörn Schmedt auf der Günne*a
}

\begin{abstract}
A new synthesis route for phosphates in an organic solvent at low temperatures is presented. The synthesis was done by dispersing a nitrate salt and phosphorus pentoxide in dimethyl sulfoxide. The synthesis can be performed under water-free conditions and yielded several organic and inorganic phosphates. Crystal structure solution of bistetramethylammonium hydrogencyclotriphosphate, $\left[\mathrm{N}\left(\mathrm{CH}_{3}\right)_{4}\right]_{2} \mathrm{HP}_{3} \mathrm{O}_{9}$, was achieved by combining information gained from powder $\mathrm{X}$-ray diffraction, liquid NMR and solid state (2D) NMR. The molecular structure of rubidium cyclotetraphosphate, $\mathrm{Rb}_{4} \mathrm{P}_{4} \mathrm{O}_{12}$, was determined using liquid state NMR and solid state (2D) NMR spectroscopy.
\end{abstract}

\section{Introduction}

Phosphates are commonly used as flame retardant additives, ${ }^{1-3}$ heterogeneous catalysts in organic synthesis, ${ }^{4}$ non-linear optic materials, ${ }^{5}$ luminescent materials, ${ }^{6-8}$ cathode materials for rechargeable batteries ${ }^{9-11}$ and ion conductors. ${ }^{12-15}$ The targeted materials often require anhydrous experimental conditions to ensure water exclusion from synthesis.

There are several synthesis routes for obtaining phosphates as reported by Durif. ${ }^{16}$ The most common routes in aqueous solution are the Boullé's process, ${ }^{17}$ ion-exchange techniques, ${ }^{18}$ crystallization in $\mathrm{H}_{2} \mathrm{O}^{19}$ and gel diffusion techniques. ${ }^{20}$ Functional materials based on nanoscale phosphates can be prepared via polyol-mediated synthesis. ${ }^{21,22}$ The most usual synthesis routes at high temperatures are hydrothermal syntheses, ${ }^{23,24}$ flux methods ${ }^{25}$ and solid state reactions (calcination). ${ }^{26}$ Thermal methods can often be supported by mechanochemical activation. ${ }^{27-29}$ To the best of our knowledge no synthesis routes for ionic phosphates are known which combine low temperature, non-aqueous solutions and $\mathrm{P}_{4} \mathrm{O}_{10}$ as a starting material.

The presented synthesis is based on the idea that the nitrate salt $\mathrm{M}\left(\mathrm{NO}_{3}\right)_{x}\left(\mathrm{M}^{x+}\right.$ being an organic or inorganic cation, $x$ is 1 or 2 for mono- or divalent cations, respectively) can be thought of as the source for " $\mathrm{M}_{x} \mathrm{O}$ " which subsequently reacts with $\mathrm{P}_{4} \mathrm{O}_{10}$ in dimethyl sulfoxide (DMSO). This hypothesis is

\footnotetext{
${ }^{a}$ Inorganic Materials Chemistry, University of Siegen, Adolf Reichwein-Straße 2, D-57068 Siegen, Germany. E-mail: schmedt_auf_der_guenne@chemie.uni-siegen.de ${ }^{b}$ Department of Chemistry, University of Munich, Butenandtstraße 5-13, D-81377 Munich, Germany $\dagger$ Electronic supplementary information (ESI) available. See DOI: 10.1039/c4dt00544a
}

corroborated by the observation of brown gases (nitrogen oxides) and the finding that polyphosphates are produced (vide infra).

Formally, the total reaction can be described by the following equation:

$$
4 / x \mathrm{M}\left(\mathrm{NO}_{3}\right)_{x}+\mathrm{P}_{4} \mathrm{O}_{10} \stackrel{\Delta, \text { DMSO }}{\longrightarrow} \mathrm{M}_{4 / x} \mathrm{P}_{4} \mathrm{O}_{12}+4 \mathrm{NO}_{2}+\mathrm{O}_{2}
$$

In this contribution we provide evidence for the feasibility of this approach by characterization of reaction products of different nitrates with a combination of NMR and diffraction techniques.

\section{Experimental}

All solid educts were stored inside a glove box (MBraun, Garching, Germany) filled with dry argon. Every synthesis step was done under argon atmosphere using air-free techniques. In general we used for the described synthesis approach temperatures spanning a range from $58{ }^{\circ} \mathrm{C}$ to $135{ }^{\circ} \mathrm{C}$ and reaction times from 12 to 72 hours. An explanation for the long reactions times are the small solvent products of reagents and products in DMSO.

For synthesis of bistetramethylammonium (TMA) hydrogencyclotriphosphate $2.5 \mathrm{mmol}$ (354.8 $\mathrm{mg}$ ) phosphorus pentoxide (Riedel de Haën, 99\%) and $5.0 \mathrm{mmol}(680.8 \mathrm{mg}$ ) TMA nitrate (Alfa Aesar, 98\%) were mixed. Subsequently $10 \mathrm{~mL}$ dimethyl sulfoxide (DMSO, Sigma Aldrich, anhydrous, >99.9\%) was added dropwise under ice cooling. Cooling helps to reduce the product spectrum. We observed a wider product spectrum without cooling possibly due to decomposition reactions of DMSO. After reaching room temperature the suspension was heated to $58{ }^{\circ} \mathrm{C}$ for twelve hours. The obtained product was 
precipitated and washed five times with acetonitrile (Sigma Aldrich, 99.9\%). A colourless phase pure powder was obtained.

For synthesis of rubidium cyclotetraphosphate $0.58 \mathrm{mmol}$ (165.0 mg) phosphorus pentoxide (Riedel de Haën, 99\%) and $2.32 \mathrm{mmol}$ (342.1 mg) rubidium nitrate (Alfa Aesar, 99\%) were mixed. Subsequently $2.5 \mathrm{~mL}$ dimethyl sulfoxide (Sigma Aldrich, anhydrous, >99.9\%) was added dropwise under ice cooling. After reaching room temperature the suspension was heated to $135{ }^{\circ} \mathrm{C}$ for 72 hours. The obtained product was washed three times with acetonitrile (Sigma Aldrich, 99.9\%). A colourless powder was obtained.

\section{Solid-state NMR spectroscopy}

For all measurements the ${ }^{1} \mathrm{H}$ resonance of $1 \% \mathrm{Si}\left(\mathrm{CH}_{3}\right)_{4}$ in $\mathrm{CDCl}_{3}$ served as an external secondary reference using the $\Xi$ values for ${ }^{13} \mathrm{C},{ }^{15} \mathrm{~N}$ and ${ }^{31} \mathrm{P}$ as reported by the IUPAC. ${ }^{30}$

The ${ }^{1} \mathrm{H}$ and ${ }^{31} \mathrm{P}$ solid-state NMR spectra were measured on a Bruker Avance II-200 spectrometer operating at the frequencies of 200.18 and $81.03 \mathrm{MHz}$, respectively (magnetic field strength $B_{0}=4.7 \mathrm{~T}$ ). Magic angle sample spinning (MAS) was carried out with a commercial $2.5 \mathrm{~mm}$ double resonance MAS probe.

The ${ }^{31} \mathrm{P}\left\{{ }^{1} \mathrm{H}\right\}$ MAS spectrum of (TMA) ${ }_{2} \mathrm{HP}_{3} \mathrm{O}_{9}$ was obtained at a sample spinning frequency of $6 \mathrm{kHz}$ with a repetition delay of 128 s. Proton decoupling was implemented using continuous wave $(\mathrm{CW})$ decoupling with a nutation frequency of $100 \mathrm{kHz}$. The ${ }^{31} \mathrm{P}^{31} \mathrm{P}$ 2D double-quantum (DQ) singlequantum (SQ) correlation MAS-NMR spectrum was obtained at a sample spinning frequency of $6 \mathrm{kHz}$ with a repetition delay of $20 \mathrm{~s}$ using a transient adapted PostC7 sequence $^{31,32}$ with a conversion period of $1.3 \mathrm{~ms}$ and rotor-synchronized data sampling of the indirect dimension. It accumulated 64 transients/FID. Proton decoupling was implemented using CW decoupling with a nutation frequency of $120 \mathrm{kHz}$.

Furthermore ${ }^{1} \mathrm{H},{ }^{13} \mathrm{C},{ }^{15} \mathrm{~N}$ and ${ }^{31} \mathrm{P}$ solid-state MAS NMR spectra were recorded at ambient temperature on a Bruker Avance III spectrometer with an $11.7 \mathrm{~T}$ magnet, operating at the frequencies of $500.25,125.79,50.71$ and $202.51 \mathrm{MHz}$, respectively. For ${ }^{1} \mathrm{H}$ and ${ }^{31} \mathrm{P}$ measurements magic angle sample spinning was carried out with a commercial $2.5 \mathrm{~mm}$ and for ${ }^{13} \mathrm{C}$ and ${ }^{15} \mathrm{~N}$ with a commercial $4 \mathrm{~mm}$ double resonance MAS probe. The ${ }^{31} \mathrm{P}\left\{{ }^{1} \mathrm{H}\right\}$ MAS spectrum of $\mathrm{Rb}_{4} \mathrm{P}_{4} \mathrm{O}_{12}$ was obtained at a sample spinning frequency of $25 \mathrm{kHz}$ with a repetition delay of $1200 \mathrm{~s}$. Proton decoupling was implemented using CW decoupling with a nutation frequency of $100 \mathrm{kHz}$. The ${ }^{1} \mathrm{H}$ spectrum was gained with a spin echo experiment at a sample spinning frequency of $25 \mathrm{kHz}$ and with a repetition delay of $8 \mathrm{~s}$. Moreover the ${ }^{15} \mathrm{~N}\left\{{ }^{1} \mathrm{H}\right\}$ spectrum based on ramped cross-polarization $^{33}$ (CP) with magic angle spinning was obtained at a sample spinning frequency of $5 \mathrm{kHz}$ with a recycle delay of $8 \mathrm{~s}$. The ${ }^{13} \mathrm{C}\left\{{ }^{1} \mathrm{H}\right\}$ MAS spectra based on ramped $\mathrm{CP}$ was obtained at a sample spinning frequency of $5 \mathrm{kHz}$ with a recycle delay of $8 \mathrm{~s}$. In both cases proton decoupling was achieved using TPPM decoupling with a nutation frequency of $22 \mathrm{kHz}$. 2D ${ }^{31}{ }^{\mathrm{P}-}{ }^{1} \mathrm{H}$-heteronuclear-correlation MAS NMR spectra were obtained with a $2 \mathrm{D}$ correlation experiment based on the PRESTO-II pulse sequence ${ }^{34}$ as described in ref. 35 . Proton decoupling was implemented using TPPM decoupling with a nutation frequency of $115 \mathrm{kHz}$. The nutation frequency for the $\mathrm{R} 18^{5}{ }_{2}$ recoupling sequence used a ${ }^{1} \mathrm{H}$ nutation frequency of $112.5 \mathrm{kHz}$ for the R-elements which consisted of simple $\pi$-pulses. All other hard pulses used on both channels were implemented with a nutation frequency of $100 \mathrm{kHz}$. Both experiments were performed at $25 \mathrm{kHz}$ sample rotation frequency and accumulated 8 transients/FID. Coherence transfer pathway selection was achieved with an 8 step phase-cycle. For (TMA) ${ }_{2} \mathrm{HP}_{3} \mathrm{O}_{9}$ and $\mathrm{Rb}_{4} \mathrm{P}_{4} \mathrm{O}_{12}$ we used a recycle delay of 6 and $32 \mathrm{~s}$, respectively. The ${ }^{31}{ }^{3}-{ }^{31} \mathrm{P} 2 \mathrm{D}$ double-quantum (DQ) singlequantum (SQ) correlation MAS-NMR spectrum of $\mathrm{Rb}_{4} \mathrm{P}_{4} \mathrm{O}_{12}$ was obtained at a sample spinning frequency of $20 \mathrm{kHz}$ with a repetition delay of $49 \mathrm{~s}$ using a transient adapted PostC7 sequence $^{31,32}$ with a conversion period of $1.2 \mathrm{~ms}$ and rotorsynchronized data sampling of the indirect dimension. It accumulated 16 transients/FID. We used rotor synchronized $t_{1}$ increments for all 2D experiments and acquired data according to the States method. ${ }^{36}$ The ${ }^{31} \mathrm{P}\left\{{ }^{1} \mathrm{H}\right\}$ C-REDOR experiment using the POST C-element ${ }^{37,38}$ was obtained at a sample spinning frequency of $25 \mathrm{kHz}$ with a repetition delay of $32 \mathrm{~s}$ and accumulated 16 transients/FID. Coherence transfer pathway selection was achieved with a 16 step phase-cycle.

\section{Powder X-ray diffraction}

The powder X-ray diffraction pattern of $(\mathrm{TMA})_{2} \mathrm{HP}_{3} \mathrm{O}_{9}$ was recorded at $298 \mathrm{~K}$ on a STOE Stadi P powder diffractometer (STOE, Darmstadt, Germany) in Debye-Scherrer geometry (capillary inner diameter: $0.48 \mathrm{~mm}$ ) by using Ge(111)-monochromated CuK $\alpha 1$ radiation (154.0596 pm) and a positionsensitive detector. Extraction of the peak positions and pattern indexing and Rietveld refinement were carried out by using the TOPAS package. ${ }^{39}$ Indexing by using the SVD method yielded an orthorhombic unit cell with parameters $a=10.506$, $b=10.986$ and $c=30.339 \AA$.

Structure solution was done with parallel tempering by using the $\mathrm{FOX}^{40}$ program. The molecules were restrained in different ways: cyclic phosphate units with the flexibility model "automatic from restraints, strict" and TMA units with the flexibility model "rigid bodies". The molecules chosen reflect the prior knowledge due to the NMR experiments. Rietveld refinement of the final structure model was realized by applying the fundamental parameter approach implemented in TOPAS (direct convolution of source emission profiles, axial instrument contributions, crystallite size and micro-strain effects). ${ }^{41}$ For the TMA cation the bond lengths ${ }^{42}$ of $\mathrm{C}-\mathrm{H}$ were constrained to $0.96 \AA$ and $\mathrm{N}-\mathrm{C}-\mathrm{H}$ angles to $108.4^{\circ}$ (average value of a TMA salt via neutron diffraction analysis given in ref. 43). The position of $\mathrm{H} 97$ was constrained to the center of the straight line between $\mathrm{O} 7$ and $\mathrm{O}^{\prime}$ from a neighbouring cyclotriphosphate unit. This is consistent with the presence of a strong (linear) hydrogen bond. ${ }^{44}$ The crystallographic data and further details of the data collection are given in Table 2 . The positional and displacement parameters are shown in Table 3. The experimental powder diffraction pattern, the 


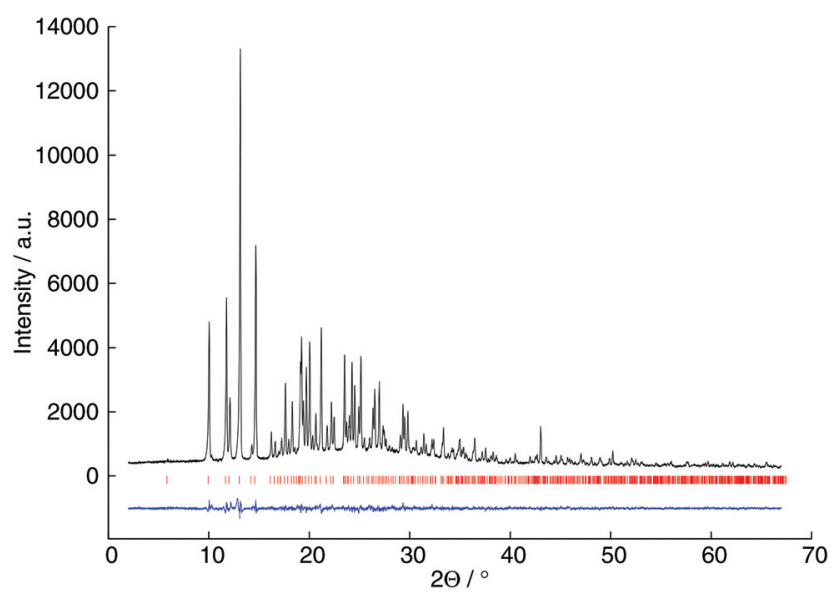

Fig. 1 Observed (black line) powder diffraction pattern of (TMA) ${ }_{2} \mathrm{HP}_{3} \mathrm{O}_{9}$ $\left(\mathrm{Cu}_{\mathrm{K \alpha 1}}, 154.06 \mathrm{pm}\right)$ as well as the difference profile (blue line) of the Rietveld refinement. Peak positions are marked by vertical red lines.

difference profile of Rietveld refinement and peak positions are shown in Fig. 1.

\section{Results and discussion}

All products that we were able to trace by NMR so far, are related to $\mathrm{P}_{4} \mathrm{O}_{10}$ by selectively breaking $\mathrm{P}-\mathrm{O}-\mathrm{P}$ bonds, thus only mono-, di-, tri, cyclotri- and tetraphosphate were present but no higher polyphosphates. If $\mathrm{H}_{2} \mathrm{O}$ is used as reagent, different hydrogenphosphates can be synthesized, for example (TMA) ${ }_{2} \mathrm{HP}_{3} \mathrm{O}_{9}$ (see below). We note in passing that the mixture of the solvent dimethyl sulfoxide and $\mathrm{P}_{4} \mathrm{O}_{10}$ is known in organic chemistry as "Onodera reagent" as a soft reagent for oxidizing alcohols which involves the formation of esters. ${ }^{45}$ In this contribution we analyzed the products starting from TMA nitrate and rubidium nitrate following the described recipe which proves the formation of different polyphosphates.

\section{Bistetramethylammonium hydrogencyclotriphosphate}

To unambiguously identify the structure of (TMA) ${ }_{2} \mathrm{HP}_{3} \mathrm{O}_{9}$ we characterized it by X-ray diffraction and NMR spectroscopy. The X-ray diffraction data were recorded from a powdered sample in a sealed glass capillary because suitable single crystals could not be obtained, despite several tries under different conditions. The structure solution had to respect constraints obtained from 1D and 2D NMR experiments, namely a limitation to three crystallographic orbits for the $\mathrm{P}$ atoms within the same cyclotriphosphate group (see NMR section below) which allow the definition of an asymmetric unit made of molecular units. This turns the structure solution into a simple task, despite the likely positional disorder in the tetramethylammonium ions. After indexing and a LeBail fit, all of the likely space groups are subjected to a "multiple world simulation" within the $\mathrm{FOX}^{40}$ program. P atoms on special positions are not to be expected because of 3 crystallographic $\mathrm{P}$ atoms in a single cyclotriphosphate anion evident through
${ }^{31} \mathrm{P}$ 2D NMR spectroscopy (see below). Repeatedly, the same solution in the space group Pcab was found after parallel tempering of the 7 best space groups. The second best solution (Pca21) has an about 8 times bigger cost function than the solution in Pcab. The solution is in full agreement with the observed ${ }^{31} \mathrm{P},{ }^{1} \mathrm{H},{ }^{13} \mathrm{C}$ and ${ }^{15} \mathrm{~N}$ NMR spectra.

All observed reflections were indexed on the basis of orthorhombic unit cell parameters $a=10.5057, b=10.9861, c=$ $30.3397 \AA$ and according to that (TMA) ${ }_{2} \mathrm{HP}_{3} \mathrm{O}_{9}$ turned out to be the only crystalline phase. A Rietveld refinement was performed in space group Pcab with a structure model that contained three phosphorus, nine oxygen, two nitrogen and eight carbon atoms in the asymmetric unit. Due to the low scattering power of hydrogen its positions are difficult to determine by X-ray diffraction. Therefore the hydrogen positions were constrained based on neutron diffraction analysis data of a TMA salt. Additional information about the hydrogen atoms are presented in the NMR section.

For the NMR study (TMA) $)_{2} \mathrm{HP}_{3} \mathrm{O}_{9}$ was completely dissolved in $\mathrm{D}_{2} \mathrm{O}$ to measure a ${ }^{31} \mathrm{P}$ liquid $\mathrm{NMR}$ spectrum, where a single signal with a chemical shift of $-20.91 \mathrm{ppm}$ can be observed. This is in agreement with the spectrum of a cyclotriphosphate. ${ }^{46}$

The quantitative ${ }^{1} \mathrm{H}$ MAS NMR spectrum (Fig. 2) features a peak at $3.1 \mathrm{ppm}$ that can be assigned to the TMA and a peak at $15.3 \mathrm{ppm}$ that is typical for a strong hydrogen bond ${ }^{47}$ between oxygen atoms of cyclotriphosphate units. The signal intensity ratio of $24: 1$ is in agreement with the chemical formula (TMA $)_{2} \mathrm{HP}_{3} \mathrm{O}_{9}$ determined from X-ray diffraction.

The ${ }^{31} \mathrm{P}\left\{{ }^{1} \mathrm{H}\right\}$ MAS NMR spectrum of (TMA) ${ }_{2} \mathrm{HP}_{3} \mathrm{O}_{9}$ (Fig. 3) displays signals of three different crystallographic orbits of phosphorus atoms at $-20.7,-24.5$ and $-26.5 \mathrm{ppm}$. Note that no signal is visible at $\delta=-45.9 \mathrm{ppm}$, which indicates that $\mathrm{P}_{4} \mathrm{O}_{10}$ reacts quantitatively.

The homonuclear ${ }^{31} \mathrm{P}$ MAS single-quantum (SQ) doublequantum (DQ) correlation spectrum (Fig. 4) proves that these three signals belong to one crystalline phase due to the correlation peaks between them. Furthermore this correlation pattern is consistent with that of a cyclotriphosphate.

The heteronuclear $2 \mathrm{D}{ }^{31} \mathrm{P}\left\{{ }^{1} \mathrm{H}\right\}$ MAS correlation spectrum of (TMA) $)_{2} \mathrm{HP}_{3} \mathrm{O}_{9}$ (Fig. 5) indicates spatial proximity between phosphorus and hydrogen atoms. A correlation peak can only be

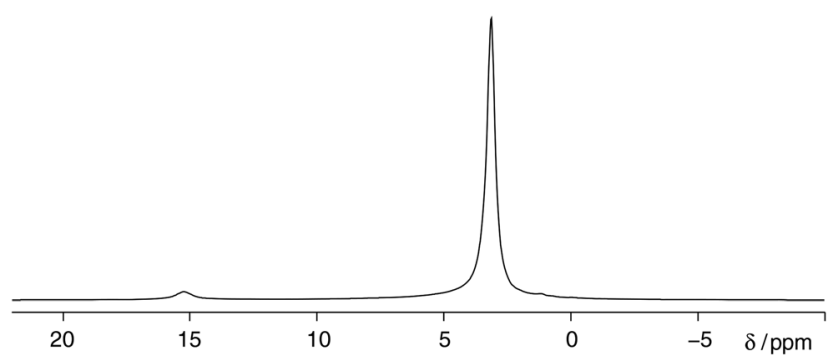

Fig. $2{ }^{1} \mathrm{H}$ MAS NMR spectrum of $(T M A)_{2} \mathrm{HP}_{3} \mathrm{O}_{9}$ measured at a sample spinning frequency of $25 \mathrm{kHz}$. The peak at $3.1 \mathrm{ppm}$ can be assigned to the TMA cation and the peak at $15.3 \mathrm{ppm}$ is typical for a strong hydrogen bond. 


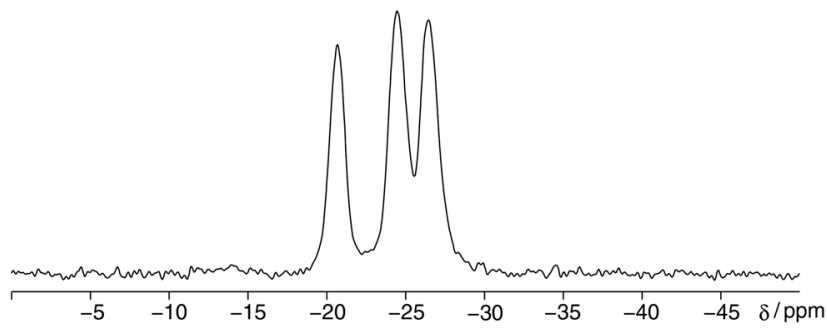

Fig. 3 Isotropic signals in a ${ }^{31} \mathrm{P}$ MAS NMR spectrum of $(T M A)_{2} \mathrm{HP}_{3} \mathrm{O}_{9}$ obtained at a sample spinning frequency of $6 \mathrm{kHz}$. The spectrum shows three signals corresponding to three different crystallographic orbits of phosphorus atoms.

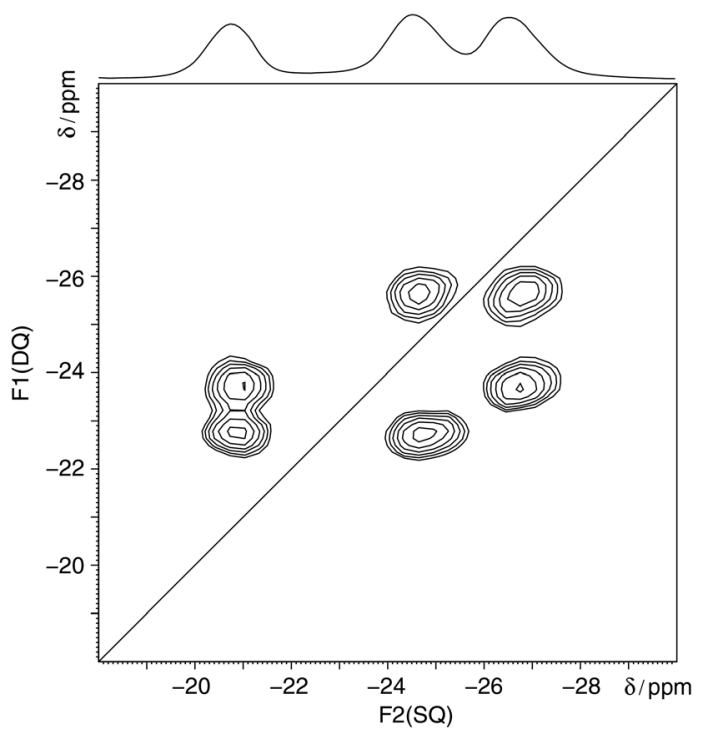

Fig. 4 Homonuclear ${ }^{31} \mathrm{P}-{ }^{31} \mathrm{P}$ MAS NMR single-quantum doublequantum correlation spectrum of $(T M A)_{2} \mathrm{HP}_{3} \mathrm{O}_{9}$ obtained at a sample spinning frequency of $6 \mathrm{kHz}$. The 1D projection at the top of the 2D spectrum stems from a separate one-pulse experiment. Correlation peaks are shown via contour plots. The diagonal line refers to the hypothetic peak position of two isochronous spins (autocorrelation diagonal). ${ }^{31,32}$

observed in the case of close ${ }^{31} \mathrm{P}-{ }^{1} \mathrm{H}$ vicinity. As there are correlation peaks between the ${ }^{1} \mathrm{H}$ signal at $3.1 \mathrm{ppm}$ and all three ${ }^{31} \mathrm{P}$ signals we conclude that every phosphorus site of the cyclotriphosphate is close to a TMA molecule. In contrast the ${ }^{1} \mathrm{H}$ signal at $15.3 \mathrm{ppm}$ correlates only with the two ${ }^{31} \mathrm{P}$ peaks at -24.5 and $-26.5 \mathrm{ppm}$. This denotes that these two phosphorus sites are closer to the strong hydrogen bond than the third one. A higher correlation signal intensity can be observed for the peak at $-24.5 \mathrm{ppm}$ than for the one at $-26.5 \mathrm{ppm}$, which indicates that the hydrogen atom in the H-bond is located closer to the $\mathrm{P}$ atom with the chemical shift of $-24.5 \mathrm{ppm}$. Thereby the nearest $\mathrm{P}-\mathrm{H}$ distances are: $\mathrm{P} 1-\mathrm{H} 97=2.3767, \mathrm{P} 1-$ $\mathrm{H} 232=3.1455, \mathrm{P} 2-\mathrm{H} 142=2.9717, \mathrm{P} 2-\mathrm{H} 131=3.2154, \mathrm{P} 2-\mathrm{H} 111$ $=3.2513, \mathrm{P} 2-\mathrm{H} 122=3.3473, \mathrm{P} 3-\mathrm{H} 97=2.5364, \mathrm{P} 3-\mathrm{H} 242=$ $3.3110, \mathrm{P} 3-\mathrm{H} 111=3.3656$ А․

The crystal structure of (TMA) ${ }_{2} \mathrm{HP}_{3} \mathrm{O}_{9}$ (Fig. 6) can be described by a chainlike arrangement of cyclotriphosphate units (orange

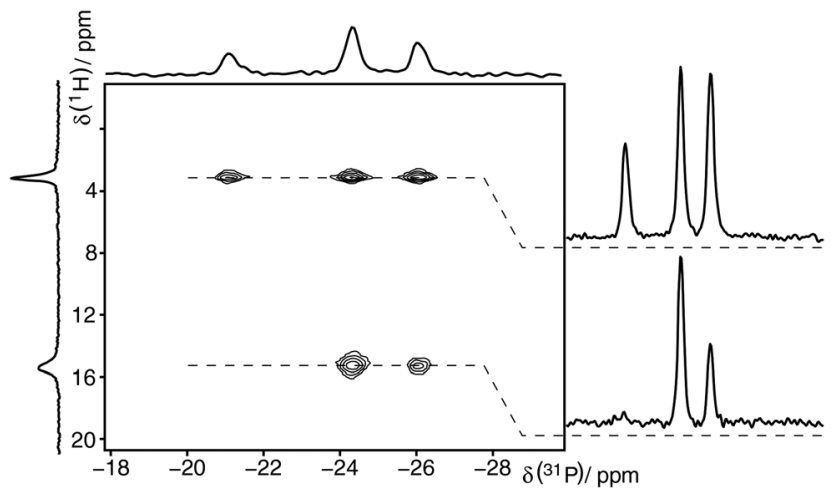

Fig. $5{ }^{31} \mathrm{P}\left\{{ }^{1} \mathrm{H}\right\}$ Heteronuclear correlation MAS NMR spectrum of $(T M A)_{2} \mathrm{HP}_{3} \mathrm{O}_{9}$ measured at a sample spinning frequency of $25 \mathrm{kHz}$. Correlation peaks are shown via contour plots. ${ }^{34,35}$

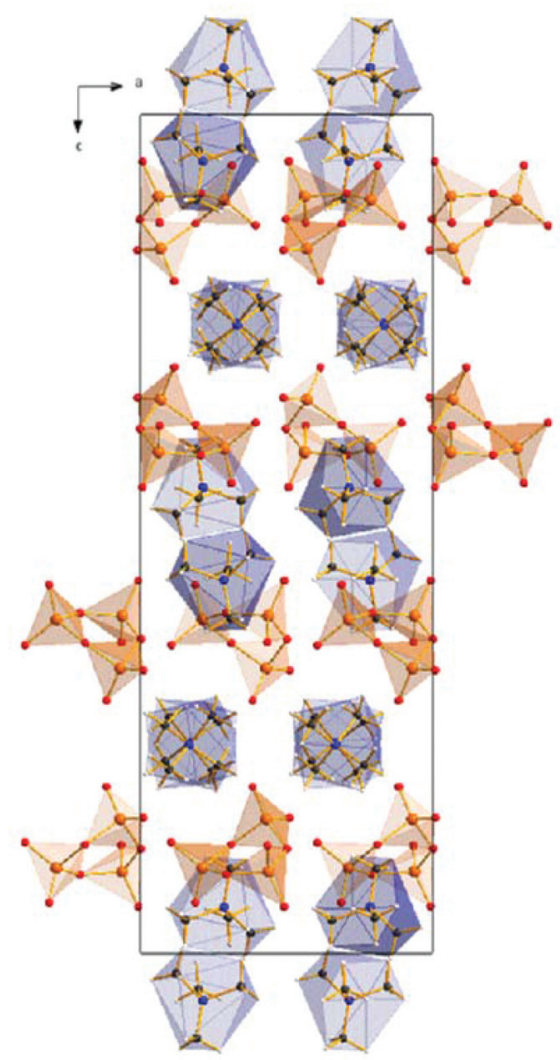

Fig. 6 Crystal structure of $(\mathrm{TMA})_{2} \mathrm{HP}_{3} \mathrm{O}_{9}$ viewed along [010]. Blue polyhedra: TMA, orange polyhedra: cyclotriphosphate. Orange spheres: phosphorus, red spheres: oxygen, blue spheres: nitrogen, black spheres: carbon, white spheres: hydrogen.

polyhedra) which are linked by strong hydrogen bonds. The gaps are filled by the TMA cations indicated by the blue polyhedra. The empirical formula of (TMA) ${ }_{2} \mathrm{HP}_{3} \mathrm{O}_{9}$ was clearly determined by structure solution and solid-state NMR study.

\section{Rubidium cyclotetraphosphate and orthophosphate}

An example of an inorganic phosphate will be presented by discussing the case of the hitherto unknown phase of $\mathrm{Rb}_{4} \mathrm{P}_{4} \mathrm{O}_{12}$. 
The existence of this cyclotetraphosphate was confirmed using liquid and solid state NMR only, because the phase of $\mathrm{Rb}_{4} \mathrm{P}_{4} \mathrm{O}_{12}$ turned out to be X-ray amorphous. Rubidium cyclotetraphosphate occurred in mixtures with crystals of monoclinic $^{48} \mathrm{RbH}_{2} \mathrm{PO}_{4}$ and an unknown phosphorus-free crystalline side-phase. A detailed discussion of the side-phases and the amorphous character of $\mathrm{Rb}_{4} \mathrm{P}_{4} \mathrm{O}_{12}$ can be found in the ESI $\dagger$ together with additional experimental evidence. The term $\mathrm{Q}_{n}$ here refers to phosphate groups classified by the number of bridging oxygen atoms $n$.

To this end the sample was completely dissolved in water. The liquid-state ${ }^{31} \mathrm{P}$ NMR spectrum shows a single peak in $\mathrm{Q}_{2}$ range with $81 \%$ and a single peak in the $\mathrm{Q}_{0}$ range with $16 \%$ of the total peak area. ${ }^{49}$ The rest $(<3 \%)$ was distributed onto small peaks in the $\mathrm{Q}_{1}$ and $\mathrm{Q}_{2}$ range and is neglected in the following. This observation is consistent with a single phase or phase mixture consisting of cyclic phosphates and orthophosphate anions only.

The solid state NMR spectrum agrees with the quantitative liquid state NMR analysis: the ${ }^{31} \mathrm{P}\left\{{ }^{1} \mathrm{H}\right\}$ MAS NMR spectrum (Fig. 7) displays peaks 1 at -20.6 and 2 at -21.7 ppm indicating the presence of two different phosphorus environments in the $\mathrm{Q}_{2}$ regime. Peaks 3 at $-2.6,4$ at -9.8 and 5 at $-23.5 \mathrm{ppm}$ can be assigned to monoclinic $\mathrm{RbH}_{2} \mathrm{PO}_{4}{ }^{50}$ and small unknown impurities, respectively. Note the absence of the $\mathrm{P}_{4} \mathrm{O}_{10}$ peak $(\delta=-45.9 \mathrm{ppm})$ which indicates that the reaction of the reagent $\mathrm{P}_{4} \mathrm{O}_{10}$ was again quantitative.

The homonuclear ${ }^{31} \mathrm{P}-{ }^{31} \mathrm{P}$ MAS SQ-DQ correlation spectrum (Fig. 8) proves that peaks $\mathbf{1}$ and $\mathbf{2}$ belong to one phase due to the correlation peaks between them. The correlation pattern and shift range are consistent with the presence of a cyclotetraphosphate but not to a cyclotriphosphate because of the connectivity and peak areas of the $\mathrm{Q}_{2}$ peaks. Catena phosphates can be excluded due to the absence of $\mathrm{Q}_{1}$ signals.

Furthermore the absence of correlation peaks between $\mathrm{Q}_{2}$ and $\mathrm{Q}_{0}$ peaks means that the sample is a heterogeneous mixture of rubidium orthophosphate and rubidium cyclotetraphosphate.

The corresponding heteronuclear $2 \mathrm{D}{ }^{31} \mathrm{P}\left\{{ }^{1} \mathrm{H}\right\}$ MAS correlation spectrum (Fig. 9) indicates spatial proximity between phosphorus and hydrogen atoms in monoclinic $\mathrm{RbH}_{2} \mathrm{PO}_{4}$.

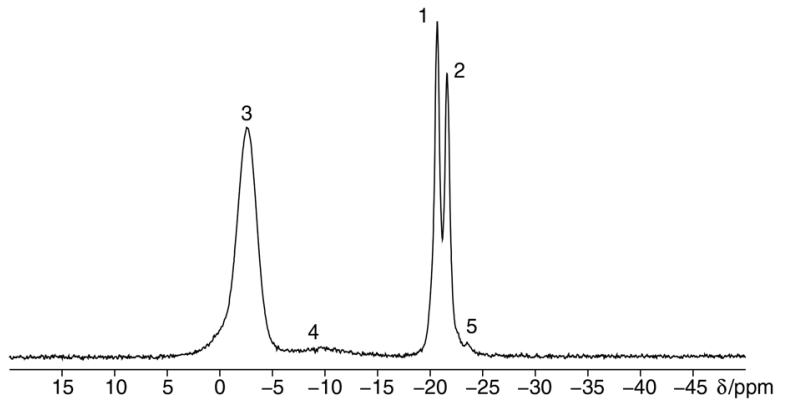

Fig. $7{ }^{31} \mathrm{P}\left\{{ }^{1} \mathrm{H}\right\}$ MAS NMR spectrum of $\mathrm{Rb}_{4} \mathrm{P}_{4} \mathrm{O}_{12}$, received at a spinning frequency of $25 \mathrm{kHz}$. Peaks 1 and 2 at -20.6 and $-21.7 \mathrm{ppm}$ indicate two different phosphorus environments. Peak 3 at $-2.6 \mathrm{ppm}$ can be assigned to monoclinic $\mathrm{RbH}_{2} \mathrm{PO}_{4}{ }^{50}$ and peaks 4 at -9.8 and 5 at $-23.5 \mathrm{ppm}$ show the marginal presence of an unknown side phase.

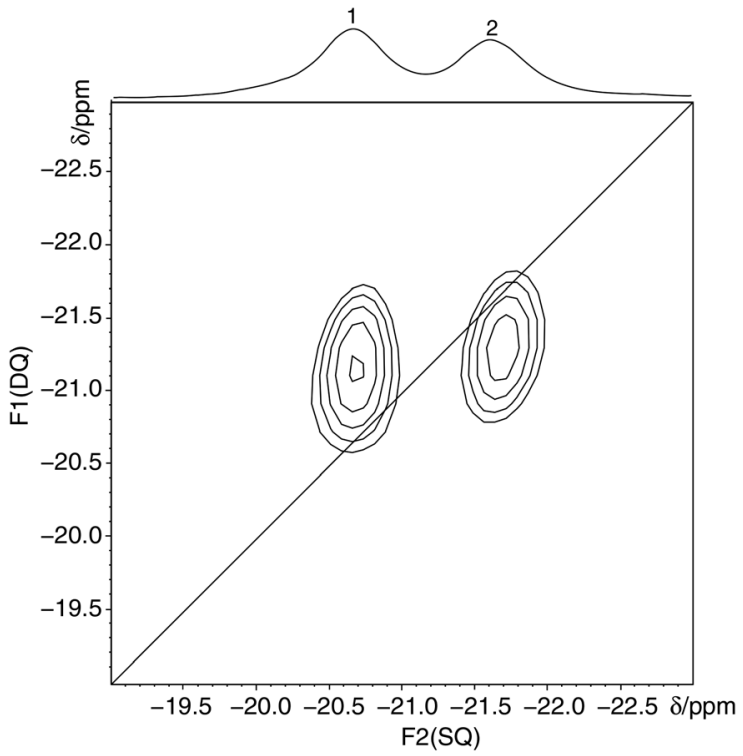

Fig. 8 Homonuclear ${ }^{31} \mathrm{P}-{ }^{31} \mathrm{P}$ MAS NMR single-quantum doublequantum correlation spectrum of $\mathrm{Rb}_{4} \mathrm{P}_{4} \mathrm{O}_{12}$ received at a sample spinning frequency of $20 \mathrm{kHz}$. The 1D projection at the top of the 2D spectrum stems from a separate one-pulse experiment. Correlation peaks are shown via contour plots. The diagonal line refers to the hypothetic peak position of two isochronous spins (autocorrelation diagonal). ${ }^{34,35}$

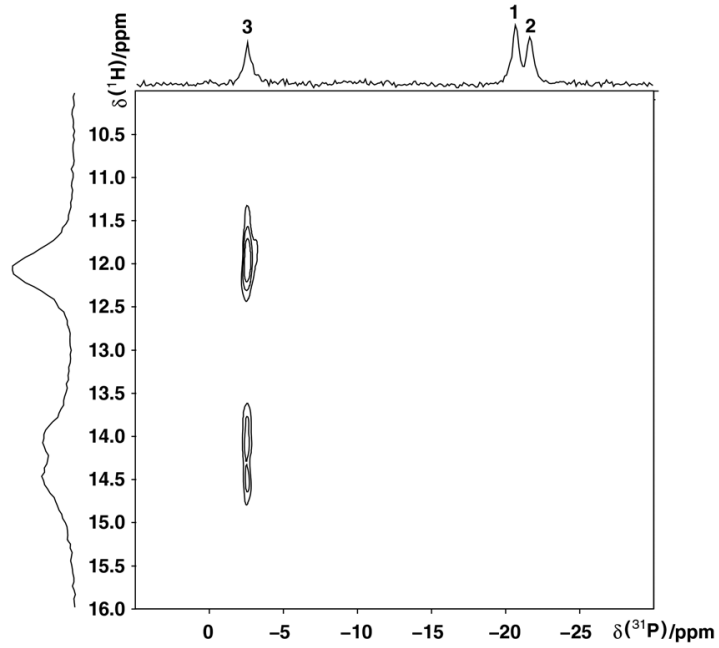

Fig. $9{ }^{31} \mathrm{P}\left\{{ }^{1} \mathrm{H}\right\}$ Heteronuclear correlation MAS NMR spectrum of $\mathrm{Rb}_{4} \mathrm{P}_{4} \mathrm{O}_{12}$ and monoclinic $\mathrm{RbH}_{2} \mathrm{PO}_{4}$ measured at a sample spinning frequency of $25 \mathrm{kHz}$. Correlation peaks are shown via contour plots. ${ }^{34,35}$

A correlation peak can only be observed in the case of ${ }^{31} \mathrm{P}-{ }^{1} \mathrm{H}$ vicinity. Absence of correlation peaks for the ${ }^{31} \mathrm{P}$ peaks 1 and 2 , suggests that the synthesized cyclotetraphosphate is hydrogen-free, in contrast to the observed correlation peaks for ${ }^{31} \mathrm{P}$ peak 3. This hypothesis was tested with the help of heteronuclear recoupling experiments.

Fig. 10 shows ${ }^{31} \mathrm{P}\left\{{ }^{1} \mathrm{H}\right\}$ C-REDOR curves of the deconvoluted peaks 1 (circles), 2 (crosses) and 3 (squares). This experiment is much more sensitive to ${ }^{31} \mathrm{P}-{ }^{1} \mathrm{H}$ proximities than cross- 


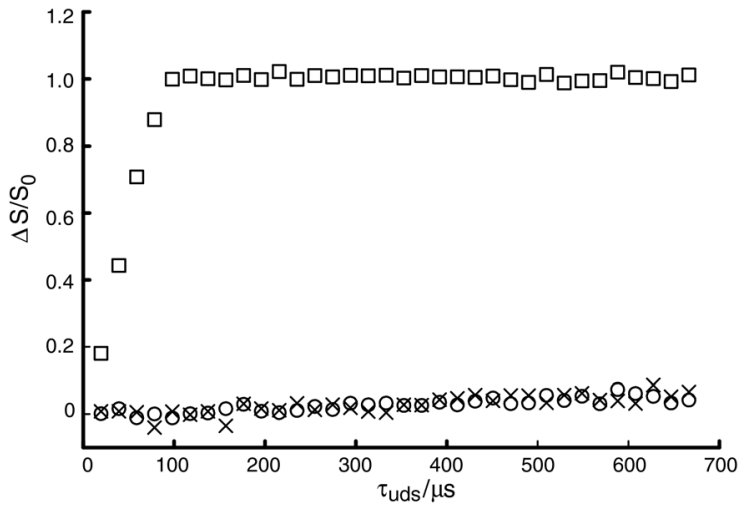

Fig. $10{ }^{31} \mathrm{P}\left\{{ }^{1} \mathrm{H}\right\} \mathrm{C}$-REDOR experiment of $\mathrm{Rb}_{4} \mathrm{P}_{4} \mathrm{O}_{12}$, measured at a spinning frequency of $25 \mathrm{kHz}$; circles belong to the peak 1 , crosses to peak 2 and squares to peak 3 as shown in Fig. 7. 37,38

Table 1 Observed isotropic chemical shift values in ppm of $(\mathrm{TMA})_{2} \mathrm{HP}_{3} \mathrm{O}_{9}, \mathrm{Rb}_{4} \mathrm{P}_{4} \mathrm{O}_{12}, \mathrm{RbH}_{2} \mathrm{PO}_{4}$ and $\mathrm{P}_{4} \mathrm{O}_{10}$

\begin{tabular}{llll}
\hline & $\delta_{\text {iso }}\left({ }^{31} \mathrm{P}\right) / \mathrm{ppm}$ & $\delta_{\text {iso }}\left({ }^{15} \mathrm{~N}\right) / \mathrm{ppm}$ & $\delta_{\text {iso }}\left({ }^{13} \mathrm{C}\right) / \mathrm{ppm}$ \\
\hline$(\mathrm{TMA})_{2} \mathrm{HP}_{3} \mathrm{O}_{9}$ & $-20.7 ;-24.5 ;-26.5$ & -337.0 & -55.1 \\
$\mathrm{Rb}_{4} \mathrm{P}_{4} \mathrm{O}_{12}$ & $-20.6 ;-21.7$ & & \\
$\mathrm{RbH}_{2} \mathrm{PO}_{4}$ & -2.6 & & \\
$\mathrm{P}_{4} \mathrm{O}_{10}$ & -45.9 & &
\end{tabular}

Table 2 Crystallographic data ${ }^{a}$ for $(T M A)_{2} \mathrm{HP}_{3} \mathrm{O}_{9}$

Crystal structure data

Formula

Formula mass $/\left(\mathrm{g} \mathrm{mol}^{-1}\right)$

Crystal system

Space group

$a / \AA$
$b / \AA$

$c / \AA$

Cell volume $/ \AA^{3}$

Z

$\rho /\left(\mathrm{g} \mathrm{cm}^{-3}\right)$ calc. from XRD

Data collection

Diffractometer

Radiation, monochromator

Detector, internal step width [ $\left.{ }^{\circ}\right]$

Temperature/K

$2 \theta$ range ${ }^{\circ}$

Step width/ ${ }^{\circ}$

Data points

Number of observed reflections

Structure refinement

Structure refinement method

Program used

Background function/parameters

shifted

Number of atomic parameters

Number of profile and other

parameters

Constraints/restraints $\quad 90 / 0$

$\chi^{2}-1.194$

$R_{\mathrm{p}} \quad 0.0330$

$\mathrm{w} R_{\mathrm{p}} \quad 0.0448$

${ }^{a}$ Estimated standard deviations are given in parentheses.
Table 3 Atomic coordinates, and isotropic displacement parameters $\left(B_{\text {iso }}\right)$ for the atoms in $(T M A)_{2} \mathrm{HP}_{3} \mathrm{O}_{9}$ (space group $\left.P c a b\right)^{a}$

\begin{tabular}{lllll}
\hline Atom & $x$ & $y$ & $z$ & $B_{\text {iso }} / \AA^{2}$ \\
\hline P1 & $0.4381(6)$ & $0.6822(6)$ & $0.5977(2)$ & $3.6(2)$ \\
P2 & $0.4308(6)$ & $0.4835(6)$ & $0.6601(2)$ & $3.7(2)$ \\
P3 & $0.2123(7)$ & $0.5225(6)$ & $0.6021(2)$ & $3.9(2)$ \\
O1 & $0.5019(10)$ & $0.5669(11)$ & $0.6251(3)$ & $2.6(4)$ \\
O2 & $0.3110(11)$ & $0.4376(9)$ & $0.6298(3)$ & $2.4(4)$ \\
O3 & $0.2935(12)$ & $0.6418(11)$ & $0.5941(4)$ & $4.6(4)$ \\
O4 & $0.5103(11)$ & $0.3734(11)$ & $0.6622(3)$ & $6.1(5)$ \\
O5 & $0.3841(10)$ & $0.5485(1)$ & $0.6985(4)$ & $3.1(4)$ \\
O6 & $0.1877(9)$ & $0.4639(10)$ & $0.5607(4)$ & $4.3(4)$ \\
O7 & $0.1055(12)$ & $0.5605(9)$ & $0.6324(3)$ & $3.8(5)$ \\
O8 & $0.4928(9)$ & $0.6930(10)$ & $0.5558(3)$ & $3.0(4)$ \\
O9 & $0.4347(10)$ & $0.7847(11)$ & $0.6289(3)$ & $1.9(4)$
\end{tabular}

${ }^{a}$ Estimated standard deviations are given in parentheses.

polarization and is used to determine heteronuclear dipoledipole coupling constants, which are closely related to internuclear distances. In agreement with the conclusions gained from the heteronuclear ${ }^{31} \mathrm{P}\left\{{ }^{1} \mathrm{H}\right\}$ MAS NMR spectrum (Fig. 9), peak 3 shows a dephased curve, due to hydrogen's vicinity. As expected, the deconvoluted curves from peaks 1 and 2 display almost no dephasing. We estimate that less than one percent of the $\mathrm{Rb}^{+}$-cations is replaced with $\mathrm{H}^{+}$-cations (Fig. 10). These findings allow us to unambiguously establish the molecular structure and composition of the previously unknown phase $\mathrm{Rb}_{4} \mathrm{P}_{4} \mathrm{O}_{12}$, which proves that the synthesis via nitrate decomposition in DMSO works also with inorganic cations (Table 1).

\section{Conclusion}

The presented novel synthesis route gives access to unknown crystalline ionic phosphates at low temperatures. The usage of anhydrous solvents allows controlling the amount of water incorporated into the crystal structures. We foresee an impact of this route onto the synthesis of organic (temperature sensitive) phosphates and onto the synthesis of water-free phosphates which are necessary for many battery materials. Furthermore the soft reaction conditions may open a new way to porous phosphates which can't be synthesized from the melt.

\section{Acknowledgements}

We want to acknowledge Prof. Wolfgang Schnick for financial support, Florian Huber and Demetria Pérez Hernández for practical support, Christian Minke for technical support at the NMR, Dominik Baumann, Phillip Pust and Sebastian Schneider for getting started with TOPAS.

\section{Notes and references}

1 S. V. Levchik and E. D. Weil, J. Fire Sci., 2006, 24, 345-364. 
2 V. Brodski, R. Peschar, H. Schenk, A. Brinkmann, E. R. H. van Eck, A. P. M. Kentgens, B. Coussens and A. Braam, J. Phys. Chem. B, 2004, 108, 15069-15076.

3 Y. E. Hyung, D. R. Vissers and K. Amine, J. Power Sources, 2003, 119-121, 383-387.

4 S. Sebti, M. Zahouily, H. B. Lazrek, J. A. Mayoral and D. J. Macquarrie, Curr. Org. Chem., 2008, 12, 203-232.

5 J. D. Bierlein and H. Vanherzeele, J. Opt. Soc. Am. B, 1989, 6, 622-633.

6 C. H. Huang, W. R. Liu and T. M. Chen, J. Phys. Chem. C, 2010, 114, 18698-18701.

7 C. K. Lin, Y. Luo, H. You, Z. Quan, J. Zhang, J. Fang and J. Lin, Chem. Mater., 2006, 18, 458-464.

8 V. Makhov, N. Y. Kirikova, M. Kirm, J. Krupa, P. Liblik, A. Lushchik, C. Lushchik, E. Negodin and G. Zimmerer, Nucl. Instrum. Methods Phys. Res., Sect. A, 2002, 486, 437- 442 .

9 W.-J. Zhang, Power Sources, 2011, 196, 2962-2970.

10 A. K. Padhi, K. S. Nanjundaswamy and J. B. Goodenough, J. Electrochem. Soc., 1997, 144, 1188-1194.

11 M. Thackeray, Nat. Mater., 2002, 1, 81-82.

12 M. Cretin and P. Fabry, J. Eur. Ceram. Soc., 1999, 19, 29312940.

13 K. Arbi, M. Tabellout and J. Sanz, Solid State Ionics, 2010, 180, 1613-1619.

14 J. Fu, J. Mater. Sci., 1998, 33, 1549-1553.

15 P. Knauth, Solid State Ionics, 2009, 180, 911-916.

16 A. Durif, Crystal Chemistry of Condensed Phosphates, Plenum Press, New York, 1995.

17 A. Boullé, C. R. Hebd. Seances Acad. Sci., 1939, 206, 517-519.

18 E. Soumhi, I. Saadoune and A. Driss, J. Solid State Chem., 2001, 156, 364-369.

19 M. Mathew and L. W. Schroeder, Acta Crystallogr., Sect. B: Struct. Crystallogr. Cryst. Chem., 1979, 35, 11-13.

20 E. Banks, R. Chianelli and R. Korenstein, Inorg. Chem., 1975, 14, 1634-1639.

21 C. Feldmann and H.-O. Jungk, J. Mater. Sci., 2002, 37, 3251-3254.

22 C. Feldmann, Adv. Funct. Mater., 2003, 13, 101-107.

23 R. A. Laudise, Chem. Eng. News, 1987, 65, 30-43.

24 J. Chen and M. S. Whittingham, Electrochem. Commun., 2006, 8, 855-858.

25 J. C. Jacco, G. M. Loiacono, M. Jaso, G. Mizell and B. Greenberg, J. Cryst. Growth, 1984, 70, 484-488.

26 R. Andrieu, R. Diament, A. Durif, M. T. Pouchot and D. Tranqui, C. R. Seances Acad. Sci., Ser. B, 1966, 262, 718-721.

27 I. Nikčević, V. Jokanović, M. Mitrić, Z. Nedić, D. Makovec and D. Uskoković, J. Solid State Chem., 2004, 177, 2565-2574.

28 O. Toprakci, H. A. K. Toprakci, L. Ji and X. Zhang, KONA Powder Part. J., 2010, 28, 50-73.
29 H.-W. Chen, C. S. Oakes, K. Byrappa, R. E. Riman, K. Brown, K. S. TenHuisen and V. F. Janas, Mater. Chem., 2004, 14, 2425-2432.

30 R. K. Harris, E. D. Becker, S. M. Cabral de Menezes, P. Granger, R. E. Hoffman and K. W. Zilm, Pure Appl. Chem., 2008, 80, 59-84.

31 M. Hohwy, H. J. Jakobsen, M. Edén, M. H. Levitt and N. C. Nielsen, J. Chem. Phys., 1998, 108, 2686-2694.

32 J. Weber, M. Seemann and J. Schmedt auf der Günne, Solid State Nucl. Magn. Reson., 2012, 43-44, 42-50.

33 G. Metz, X. L. Wu and S. O. Smith, J. Magn. Reson., Ser. A, 1994, 110, 219-227.

34 X. Zhao, W. Hoffbauer, J. Schmedt auf der Günne and M. H. Levitt, Solid State Nucl. Magn. Reson., 2004, 26, 57-64.

35 Y. S. Avadhut, J. Weber, E. Hammarberg, C. Feldmann and J. Schmedt auf der Günne, Phys. Chem. Chem. Phys., 2012, 14, 11610-11625.

36 D. J. States, R. A. Haberkorn and D. J. Ruben, J. Magn. Reson., 1982, 48, 286-292.

37 J. C. C. Chan and H. Eckert, J. Chem. Phys., 2001, 115, 6095-6105.

38 J. C. C. Chan, Chem. Phys. Lett., 2001, 335, 289-297.

39 A. A. Coelho, TOPAS-Academic, Version 4.1, Coelho Software, Brisbane, 2007.

40 V. Favre-Nicolin and R. Cherny, J. Appl. Crystallogr., 2002, 35, 734 .

41 J. Bergmann, R. Kleeberg, A. Haase and B. Breidenstein, Mater. Sci. Forum, 2000, 347-349, 303-308.

42 SHELXL User Guide, http://shelx.uni-ac-gwdg.de/SHELX/ shelxl_user_guide.pdf, link accessed 27.04.2014.

43 F. A. Cotton, P. C. W. Leung, W. J. Roth, A. J. Schultz and J. M. Williams, J. Am. Chem. Soc., 1984, 106, 117-120.

44 T. Steiner, Angew. Chem., 2002, 114, 50-80.

45 K. Onodera, S. Hirano and N. Kashimura, J. Am. Chem. Soc., 1965, 87, 4651-4652.

46 T. Glonek, J. R. Van Wazer, M. Mudgett and T. C. Myers, Inorg. Chem., 1972, 11, 567-570.

47 J. P. Yesinowski and H. Eckert, J. Am. Chem. Soc., 1987, 109, 6274-6282.

48 M. T. Averbouch-Pouchot and A. Durif, Acta Crystallogr., Sect. C: Cryst. Struct. Commun., 1985, 41, 665-667.

49 Integrating the five peaks which can be observed in the ${ }^{31} \mathrm{P}$ liquid NMR spectrum dissolved in $\mathrm{D}_{2} \mathrm{O}$ results in the following values: one peak at $0.84 \mathrm{ppm}\left(\mathrm{Q}_{0}\right)$ with a peak area of 1.75 a.u. (15.96\%), two peaks at -9.7 and -9.89 ppm $\left(\mathrm{Q}_{1}\right)$ with a combined peak area of 0.32 a.u. (2.91\%), one peak at $-20.79 \mathrm{ppm}\left(\mathrm{Q}_{2}\right)$ with a peak area of 0.11 a.u. (1\%) and one peak at $-21.55 \mathrm{ppm}\left(\mathrm{Q}_{2}\right)$ with a peak area of 8.78 a.u. (80.1\%).

50 M. Vijayakumar, A. Bain and G. Goward, J. Phys. Chem. C, 2009, 113, 17950-17957. 